\title{
Experimental Study on the Sliding of WJ-8 Small Resistance Fastener Composite Pad
}

\author{
Zhiping Zeng, ${ }^{1,2}$ Di Wang, ${ }^{1}$ Fushan Liu, ${ }^{1}$ Abdulmumin A. Shuaibu $\mathbb{D}^{1,}{ }^{1,3}$ and Zhihua Lin ${ }^{4}$ \\ ${ }^{1}$ School of Civil Engineering, Central South University, Changsha, Hunan 410075, China \\ ${ }^{2}$ MOE Key Laboratory of Engineering Structure of Heavy Haul Railway (Central South University), Ministry of Education, \\ Changsha, Hunan 410075, China \\ ${ }^{3}$ Department of Civil Engineering, Faculty of Engineering, Ahmadu Bello University, Zaria, Nigeria \\ ${ }^{4}$ Guangxi Transportation Research \& Consulting Co., Ltd., Nanning, Guangxi,530000, China
}

Correspondence should be addressed to Abdulmumin A. Shuaibu; abdulshub4u@csu.edu.cn

Received 20 October 2019; Revised 8 May 2020; Accepted 21 July 2020; Published 3 August 2020

Academic Editor: Roberto Nascimbene

Copyright ( 2020 Zhiping Zeng et al. This is an open access article distributed under the Creative Commons Attribution License, which permits unrestricted use, distribution, and reproduction in any medium, provided the original work is properly cited.

Under long-term temperature loading, long bridges stretch and deform, causing the beam and rail to move relative to each other. This phenomenon could cause a gradual slide of the rail relative to the fastener composite pad and ultimately results in the slipping out of the fastener pad at the end of the ballastless track bridge changes. The slipping out of the fastener composite pad changes the longitudinal resistance of the fastener and causes shock of the train on the rail structure due to direct contact between the rail and the tie, thus inhibiting the normal use of the line. In this paper, a reciprocating tensile test was carried out on a WJ-8 small resistance fastener to explore the breaking process of the fastener composite pad, identify the interaction mechanism of the fastener composite pad under the rail, and ultimately determine the influence of the pad on the longitudinal resistance of the fastener. The results show that the two factors that affect the longitudinal resistance of the fastener under reciprocating loading are the surface roughness and displacement of the fastener composite pad. While the surface roughness of the fastener composite pad is the main influencing factor in the early stage, the displacement of the composite pad has a greater impact on the later stage. The research results of this paper can provide an important reference for the maintenance and repair of ballastless track fasteners on bridges.

\section{Introduction}

With the development of high-speed heavy-haul transport, new structures such as the seamless tracks and ballastless tracks have correspondingly emerged. Due to the good operating functions of the seamless track, it is widely used in railways worldwide. Seamless tracks thus constitute an important symbol of railway technology progress around the world. The absence of rail joints in seamless lines has significantly improved the smoothness and ride comfort of train operations. To ensure the smooth and safe operation of high-speed trains, high-speed railways have put forward new requirements for these lines. The fastener plays a key role in maintaining the stability and reliability of the rail, as it connects the rail and the sleeper or rail board. In the design and operation of a seamless line, the fastener is a key component that determines track resistance due to its essential resistance characteristics.

Many scholars have studied the longitudinal resistance of seamless lines on different types of bridges analysed the rail stress and longitudinal stress in bridge piers and investigated the law of relative motion of beams and rails based on experimental/field measurements and a variety of wellestablished finite element models [1-11]. Under temperature loading and train loading actions, a long bridge is prone to stretch and deform at the beam end, leading to the traction of the track plate and the relative displacement of the beam and rail. This results in the fastener pad sliding against the rail. Long-term temperature loading causes the beam and rail to continue to move relative to each other, and the 
fasteners at the beam end of long-span bridges experience fatigue relative to the rail $[12,13]$. Thus, the fastener pad can move out of place. This process continues until the fastener performance can no longer meet its functional requirements of the line.

Additionally, many relevant studies have been conducted on the topic of fastener performance.

Dai et al. [14] compared the additional longitudinal force in the conventional resistance fastener and the small resistance fastener of a seamless track and reported that the small resistance fastener can reduce the additional stretching force and track braking force in the long bridge ballastless track. Xu et al. [15] studied the influence of rail fastener failure on dynamic behaviours of wheel/rail interactions and the railway tracks by considering the effects on track random irregularities. Carrascal et al. [16] studied the mechanical characteristics of the under-rail pad in the fastener system under different load conditions and temperatures. They found out that the mechanical characteristics of the underrail pad would not change much within the temperature range observed under normal working conditions. However, under conditions not within the temperature range identified, increasing the humidity could reduce the under-rail pad fatigue damage. Casado et al. [17] focused on the track gauge block, to which temperature and rail lateral displacement were applied. They reported the deformation of the fastener system under different displacement and temperature conditions and a simultaneous illumination of the deformation curve of the fastener system. Szurgott et al. [18] established finite element models for two kinds of fastener systems and analysed the stress and deformation of rubber pads under train loading. Bae et al. [19] conducted an experimental study on the longitudinal friction behaviour of seamless line rail fasteners on railway bridges in South Korea and employed statistical analysis to describe the performance characteristics of rail fasteners. Thompson and Verheij [20] carried out the dynamic test on different fastener systems to obtain the longitudinal and lateral stiffness of each system under $100 \sim 1000 \mathrm{~Hz}$ vibrations. Furthermore, the test was confirmed through a comparison with field measurement of fastener system stiffness analysed under high-frequency vibration. Oda et al. [21] conducted an experimental study on the elastic strip of a rail fastener, in combination with the theory of elastic strip buckle pressure. This method simplified the elastic strip fastener system with a spring-damping system, and subsequently, the simplified track dynamic behaviour state was analysed. Casado et al. [22] carried out relevant tests and analysed the change rules of the gauge baffle stiffness under different lateral rail displacements to discover the damage status of its structure. Szurgott and Bernyś [23] used the superposition principle to simulate the nonlinear vibration reduction behaviour of a rubber gasket of a fastener system, and they found out that the nonlinear dynamic stiffness of the rubber pad was related to the displacement amplitude and frequency. Yuan et al. [24] introduced the stochastic fractional derivative model into a vehicle-floating slab track coupled dynamics model to investigate the vibration isolation performance of the floating slab track with rubber bearings.
However, at present, there is no study conducted on the use of reciprocating tensile test on the WJ- 8 type resistance fastener to explore the sliding mechanism of the composite fastener pad and its effect on its longitudinal resistance. In this study, a reciprocating tensile test of a WJ-8 small resistance fastener was carried out to study the sliding process of the composite pad and its influence on the longitudinal resistance of the fasteners commonly used in Chinese ballastless tracks.

The WJ-8 type fastener commonly used in high-speed railway ballastless tracks is composed of screw spikes, flat washers, rail clips, rail insulators, gauge blocks, a composite pad, a tie plate, a resilient pad, and plastic dowels located on concrete sleepers. The tie plate is fastened to the track plate through screw spikes and embedded plastic dowels [25]. The connections between the components of the fastener system are depicted in Figure 1.

The structure of the ballastless track WJ-8 fastener consists of many components, and therefore, many contact interfaces exist between layers. Among them, there is the wear contact between the under-rail pad and the rail and between the under-rail pad and the iron pad. Additionally, the limit friction contact between the crossover block and the rail has a great impact on the longitudinal resistance of the WJ-8 fastener. Herein, it is necessary to explain the concepts of friction and wear due to their specific application to fasteners. When two objects are in contact with each other, or the object and the medium experience a relative motion (or relative motion tendency), the obstruction is called friction. Meanwhile, wear refers to the phenomenon of surface damage caused by a gradual separation of debris from the surface when the component surface moving relative to each other experiences contact [26]. In a WJ-8 type resistance fastener, the under-rail pad is composite. The contact between the composite pad and the rail is friction between the metal and the pad, while the contact between the composite pad and the iron pad is wear between the rubber material and the metal. The contact between the insulating gauge block and the rail is friction between the plastic and metal. Therefore, the interface contact and friction principle of a WJ-8 small resistance fastener system must be analysed at these interfaces.

The composite pad is composed of a $1.2 \mathrm{~mm}$ thick $1 \mathrm{Cr} 18 \mathrm{Ni} 9 \mathrm{Ti}$ stainless steel plate and vulcanised rubber. The upper surface of the composite pad and the rail experience contact friction and wear between metals, while the contact between the lower surface and the iron pad is contact friction and wear between rubber and metal. The process of friction and wear between the composite pad and the rail is a complex interaction, resulting from comprehensive combinations of the principles of physics, chemistry, and mechanics, and is mainly affected by the cross or simultaneous dynamic superposition of thermal, chemical, and mechanical effects. The physical mechanism of the contact friction between the composite pad and the rail can be understood as the microcutting effect of different particles of iron scraps in the friction area on the steel surface and its interfacial film, which results in the plastic deformation of the composite pad surface. 


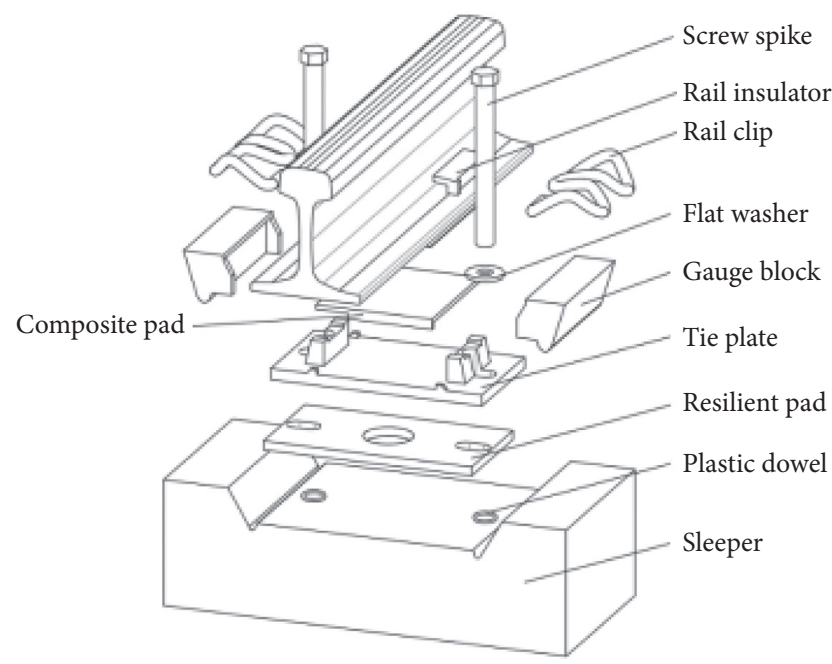

Figure 1: Components of the WJ-8 fastener system.

King and Lanchaster [27] explained that the mechanism of metal wear on the rubber is the effect produced by the microcutting of hard particles embedded in the rubber body. Ab-Malek and Stevenson [28] believed that the process of repeatedly pressing the metal head into the rubber body corresponds to the transfer film mechanism, pointing out that the wear of the rubber body in such a case is fatigue failure. Charrier et al. [29] noted that a rubber transfer layer on the metal tip surface reduced the wear of a needle. In the presently studied fastener, repeated friction due to the reciprocating movement of the rail, iron pad, and rubber pad causes the rubber pad surface to become rough. The iron pad surface metal pressure head repeatedly embedded in the rubber material causes the iron pad to wear to a certain extent, while at the same time the rubber pad surface abrasion is more serious, and chipping gradually increases. Therefore, the surface of the rubber pad becomes very rough, which ultimately increases the coefficient of friction. During the reciprocating movement of the rail, the rubber pad is driven to move together with the rail; however, the longitudinal friction of the rubber pad decreases when the rail resets. Because the rubber pad is unable to be completely reset with the rail, part of the rubber pad slips out after every cycle of reciprocating motion. As time goes on, the slide length of rubber pad increases until the rubber pad finally slides out completely. This, in turn, leads to a reduction in the effective support areas and the elasticity of the rubber pad and rail. Consequently, the vibration reduction quality is compromised. Furthermore, the longitudinal resistance of the fastener will decrease, the relative displacement of the beam rail will increase, and bottom of the rail will be empty, which may lead to rigid contact between the rail and the iron pad.

Composite pads are applied to long-span bridges to reduce the longitudinal resistance. Under the combined action of temperature and train loadings, the relative displacement of the beam and rail at the beam end of a longspan bridge will excessive, leading to the phenomenon of fastener spacers jumping out. Figure 2 shows a typical,

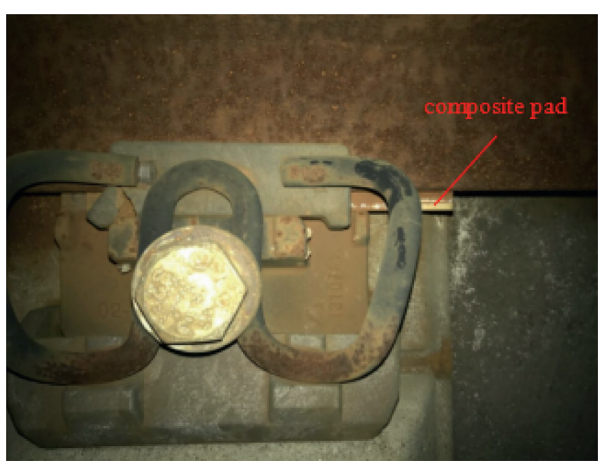

FIGURE 2: Image of the composite pad sliding.

composite pad pulled out in an existing line. The consequence of this phenomenon is the development of rigid contact at the bottom of the rail between the steel and the iron pad. This may cause the dynamic/impact force to increase as a result of increase in wheel/rail force on the track structure, thus accelerating track structure damage, causing serious stability and safety concerns.

The longitudinal resistance of the track is also an important parameter that assists in resisting the expansion of the rail and preventing the track from crawling. The longitudinal resistance of a ballastless track takes on the longitudinal resistance value of the fastener [30]. This term refers to the resistance of intermediate fasteners and anticlimbing equipment to the longitudinal movement of the road along the rail, which is mainly composed of the frictional resistance between the rail and the rubber pad surface and the frictional resistance between the fastener (elastic strip) and the rail bottom contact surface. The friction resistance depends on the buckle pressure and the friction factor of the contact surface.

\section{Materials and Methods}

In this study, the length of rail was $0.625 \mathrm{~m}$, and a WJ-8 small resistance fastener was used to buckle the rail with a torque of $110 \mathrm{kN} \cdot \mathrm{m}$. In the test system, the loading rate was set to $9 \mathrm{kN} / \mathrm{min}$, the acquisition frequency was $2 \mathrm{~Hz}$, the left and right displacement was $20 \mathrm{~mm}$, and the total displacement in one direction was $40 \mathrm{~mm}$. Two sets of jacks arranged symmetrically on both sides of the rail was used to applied the force. The longitudinal displacement component was collected via a displacement sensor. The whole system was controlled by a computer, while the force and displacement values were recorded in real-time. In addition, the tension and displacement of the rail in real-time were collected on the computer through the tension and displacement sensors. A laser displacement sensor was used to measure the displacement of the pad. The laser was directed onto the nonprotruding part of the pad so that the displacement of the pad could be monitored in real-time.

The experimental setup is shown in Figure 3. The loading was done through force-applying components that operated at intervals, using an oil inlet pipe that caused the jack to move, thereby pulling the rail and inducing longitudinal movement. The speed of the rail movement depended on the 


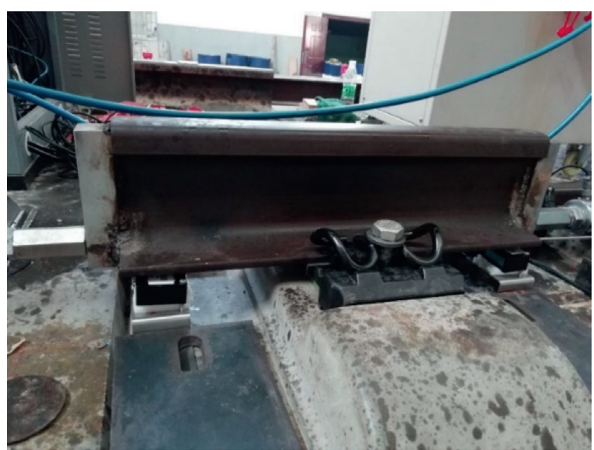

(a)

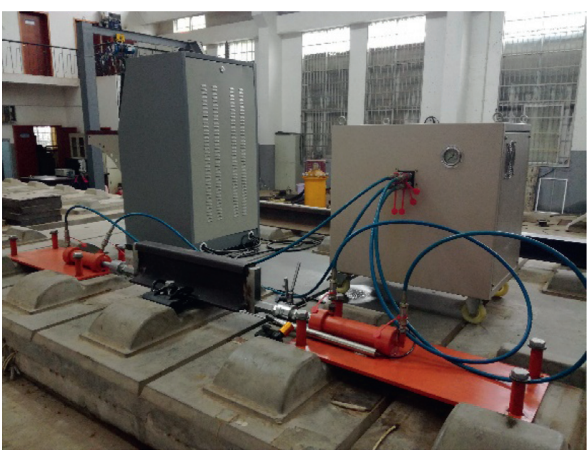

(b)

Figure 3: Diagram of the test device setup.

preset longitudinal loading rate in the software. The two force-applying components work in succession. When the displacement value set by the system was reached, the first component applying the force stopped working, and the other force-applying component automatically began to work, leading the rail to move in the reverse direction. When the preset displacement was reached, the force component stopped working, and the other force-applying component continued to work. One cycle of loading motion is said to occur when the rail returns to its initial position. The procedure was repeated until a sufficient amount of data was collected.

\section{Results and Discussion}

The number of test cycles was nearly 360 . After the test, the measured data were processed, and the longitudinal resistance $(r)$-displacement $(x)$ scatter plot of the fasteners at different loading cycles was fitted by the least-squares method using the power-exponential function form $r=a \times\left(b-e^{-c x}\right)$.

\subsection{Relationship between Longitudinal Resistance and Dis-} placement for Fasteners under Different Loading Cycles. After processing the collected data, the longitudinal resistance-displacement data corresponding to the fastener's initial state and other special key points were extracted, to establish the longitudinal resistance-displacement relationship of the fastener under different loading cycles which was obtained, as shown in Figure 4.

Figure 4 reveals that there is a large range in the longitudinal resistance of the fastener throughout the various stages of the test loading. The displacement of the rail changes when the rail slides under different loading cycles. An obvious change in the fastener sliding resistance under different loading cycles is also apparent. As the number of reciprocating loads increases from 0 to 225 cycles, the sliding resistance of the fasteners similarly increases. After 225 loading cycles, sliding resistance of the fasteners begins to decrease. The characteristic displacement point was taken to be $0.5 \mathrm{~mm}$ which is the elastic displacement point of the fastener. The results show that the longitudinal resistance of the fastener corresponding to a $0.5 \mathrm{~mm}$ displacement in the

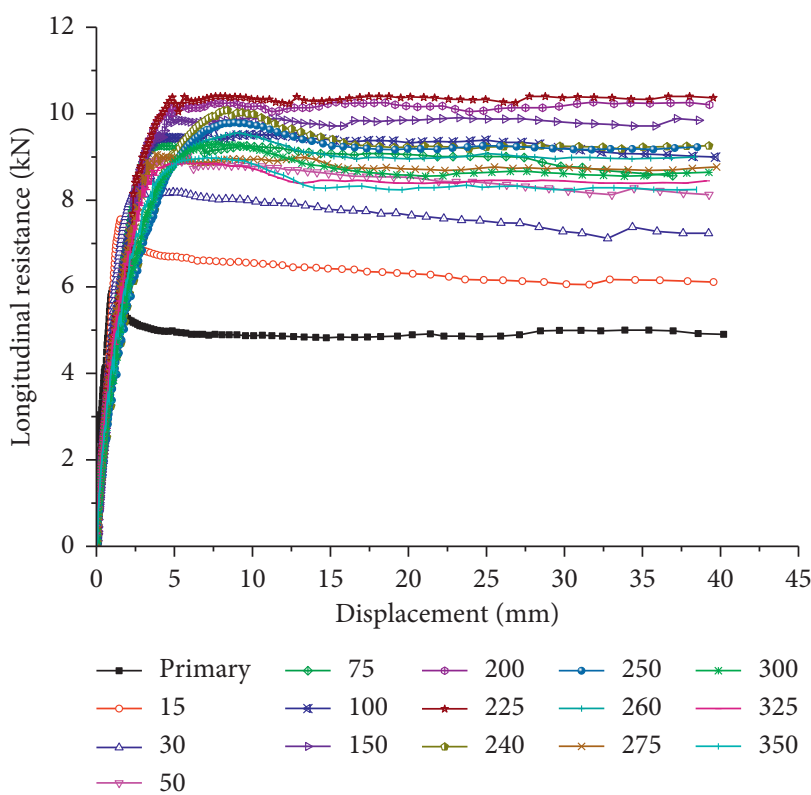

FIGURE 4: Relationship between the longitudinal resistance of the fastener and its displacement under different loading cycles.

initial state is $3.98 \mathrm{kN}$, while the longitudinal resistance of the fastener corresponding to 225 loading cycles is $2.68 \mathrm{kN}$. The differences in longitudinal resistance of the fastener between the initial state and after 225 loading cycles are $1.30 \mathrm{kN}$ for the $0.5 \mathrm{~mm}$. After 225 loading test cycles, the corresponding longitudinal resistance-displacement curve of the fastener starts to decrease. The longitudinal resistance of the fastener corresponding to $0.5 \mathrm{~mm}$ at 350 loading cycles is $2.29 \mathrm{kN}$, and the difference in the longitudinal resistance of the fastener from 225 to 350 loading times is $0.39 \mathrm{kN}$. The longitudinal resistance of the $0.5 \mathrm{~mm}$ displacement point of the fastener under different reciprocating loading cycles is shown in Table 1.

3.2. Statistical Results of Longitudinal Resistance of Fasteners under Different Reciprocating Loading Cycles. Based on the comprehensive data analysis results, the longitudinal resistance and the displacement of the fastener under different reciprocating loading cycles are shown in Table 2. 
TABLE 1: The longitudinal resistance of the $0.5 \mathrm{~mm}$ displacement point of the fastener under different reciprocating loading cycles.

\begin{tabular}{lccc}
\hline Loading cycles & Primary & 225 & 350 \\
\hline Longitudinal resistance $(\mathrm{kN})$ & 3.98 & 2.68 & 2.29 \\
\hline
\end{tabular}

TABLE 2: Relationship between longitudinal resistance $(r)$ and displacement of fasteners $(x)$ under different reciprocating loading times.

\begin{tabular}{lcccc}
\hline $\begin{array}{l}\text { Loading cycle } \\
\text { (cycle) }\end{array}$ & $\begin{array}{c}\text { Sliding resistance } \\
(\mathrm{kN})\end{array}$ & $\begin{array}{c}\text { Relational expression } r(\mathrm{kN} / \mathrm{m} / \mathrm{rail}), x \\
(\mathrm{~mm})\end{array}$ & $\begin{array}{c}\text { Correlation } \\
\text { coefficient }\end{array}$ & $\begin{array}{c}\text { Displacement of pad } \\
(\mathrm{cm})\end{array}$ \\
\hline Primary & 4.90 & $r=4.780 \times\left(1.062-e^{-3.751 x}\right)$ & 0.935 & 0.00 \\
15 & 6.54 & $r=7.474 \times\left(0.898-e^{-1.667 x}\right)$ & 0.931 & 0.04 \\
30 & 7.75 & $r=8.980 \times\left(0.895-e^{-1.152 x}\right)$ & 0.972 & 0.08 \\
50 & 8.62 & $r=9.238 \times\left(0.950-e^{-0.822 x}\right)$ & 0.988 & 0.30 \\
75 & 9.06 & $r=9.523 \times\left(0.975-e^{-0.738 x}\right)$ & 0.991 & 0.38 \\
100 & 9.36 & $r=9.709 \times\left(0.983-e^{-0.689 x}\right)$ & 0.993 & 0.45 \\
150 & 9.81 & $r=9.870 \times\left(0.995-e^{-0.556 x}\right)$ & 0.998 & 1.26 \\
200 & 10.13 & $r=9.237 \times\left(1.054-e^{-0.496 x}\right)$ & 0.990 & 1.44 \\
225 & 10.33 & $r=9.275 \times\left(1.051-e^{-0.518 x}\right)$ & 0.986 & 4.65 \\
240 & 9.21 & $r=9.455 \times\left(1.026-e^{-0.460 x}\right)$ & 0.992 & 6.33 \\
250 & 9.17 & $r=9.440 \times\left(1.015-e^{-0.456 x}\right)$ & 0.994 & 7.52 \\
260 & 8.93 & $r=9.239 \times\left(1.013-e^{-0.493 x}\right)$ & 0.996 & 8.33 \\
275 & 8.90 & $r=9.451 \times\left(0.953-e^{-0.763 x}\right)$ & 0.995 & 8.58 \\
300 & 8.56 & $r=8.852 \times\left(1.026-e^{-0.556 x}\right)$ & 0.993 & 8.72 \\
350 & 8.47 & $r=8.719 \times\left(1.008-e^{-0.653 x}\right)$ & 0.992 & \\
\hline
\end{tabular}

It can be seen from Table 2 that the correlation coefficient between the longitudinal resistance and the displacement of the fasteners under different reciprocating loading times is above 0.90 . This implies a high degree of fitting and good accuracy. With the increase in the number of reciprocating loads, the sliding resistance of the fastener first increases and then decreases. While the sliding resistance of the fastener at the initial state is $4.90 \mathrm{kN}$, after 225 loading cycles, this value increases to $10.33 \mathrm{kN}$, which represents an increase of $110.8 \%$ from the initial state. Afterwards, the sliding resistance of the fastener begins to decrease. The sliding resistance at 350 loading cycles is $8.25 \mathrm{kN}$, representing a $20.1 \%$ decrease from the sliding resistance of the fastener at 225 loading cycles. As the number of test loading cycles increases, the displacement of the pad sequentially increases. The displacement of the pad at the initial state is 0 , while the displacement of the pad at 225 loading times is $1.44 \mathrm{~cm}$, continuously loading resulted in a quick increase in the displacement of the sliding pad, and the displacement of the pad at 350 loading times is $8.73 \mathrm{~cm}$, accounting for $50.2 \%$ of the longitudinal length of the pad. When the slip out of the pad is $1.44 \mathrm{~cm}$, the sliding resistance increases from the initial $4.90 \mathrm{kN}$ to $10.33 \mathrm{kN}$, which represents an increase of $110.8 \%$ from the initial state, consequently, and then the sliding resistance begins to decrease. When the pad slips out of $8.73 \mathrm{~cm}$, the sliding resistance of the fastener is $8.25 \mathrm{kN}$, which represents a decrease of $20.1 \%$ from the sliding resistance of the fastener at $1.44 \mathrm{~cm}$ displacement of the pad. Therefore, the slipping out of the pad demonstrated a large influence on the longitudinal resistance of the fastener.

3.3. Test Data Analysis. The condition of the pad during the test is shown in Figures 5. Figure 6-10 further depict the relationships between the loading cycles and the longitudinal resistance of the fastener corresponding to the $0.5 \mathrm{~mm}$ elastic displacement point, the sliding resistance of the fastener, pad displacement, and the relationship curves between resistance and displacement.

Figure 5 demonstrates that under the reciprocating load action, the composite pad rubs against the rail and the iron pad, causing the pad surface to become worn after the repeated friction and thereby inducing the pad to move towards one side, in the longitudinal direction. The raised part of the pad is not broken, but rather flattened and squeezed into the bottom of the rail. Figure 6 indicates that as the number of reciprocating load cycles increases, the longitudinal resistance of the fastener corresponding to the $0.5 \mathrm{~mm}$ displacement gradually decreases. Though increasing and decreasing fluctuations occur during this reduction process, there is an overall decrease, so it is expected that when the loading continues, the longitudinal resistance of the fastener corresponding to the $0.5 \mathrm{~mm}$ displacement will continue to decrease. Since the $0.5 \mathrm{~mm}$ displacement corresponds to the elastic displacement of the WJ-8 small resistance fastener in the initial state and according to the corresponding relationship between the longitudinal resistance of the fastener and the loading times, the reciprocating test loading indicates that the elastic displacement of the composite pad is gradually reduced. It can be seen from Figures 7 and 8 that when the number of reciprocating load cycles increases, the sliding resistance of the fastener initially increases before gradually decreasing, and the pad displacement increases slowly until it is loaded about 225 times, after which the displacement of the pad increases rapidly. Finally, at 360 loading cycles, the displacement of the pad remains steady; at this time, a large displacement can be seen, which reaches nearly half the longitudinal length of the pad (approximately $8.5 \mathrm{~cm}$ or more). From the large 


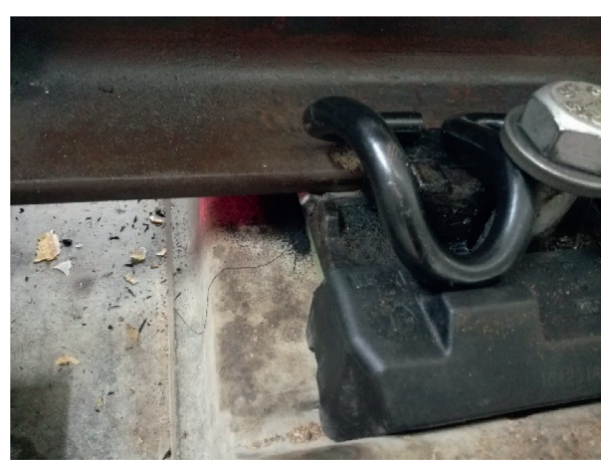

(a)

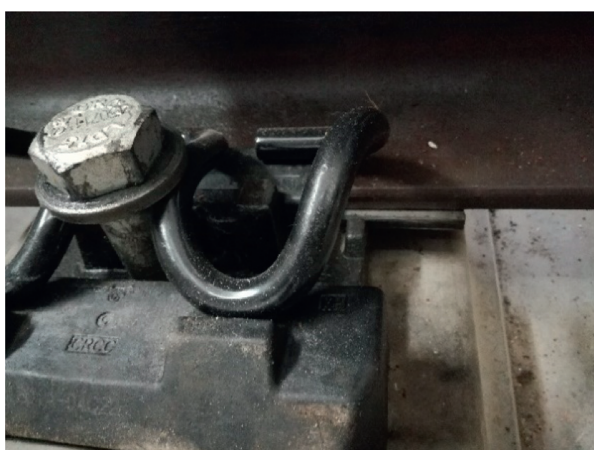

(b)

FIgURE 5: Test process picture.

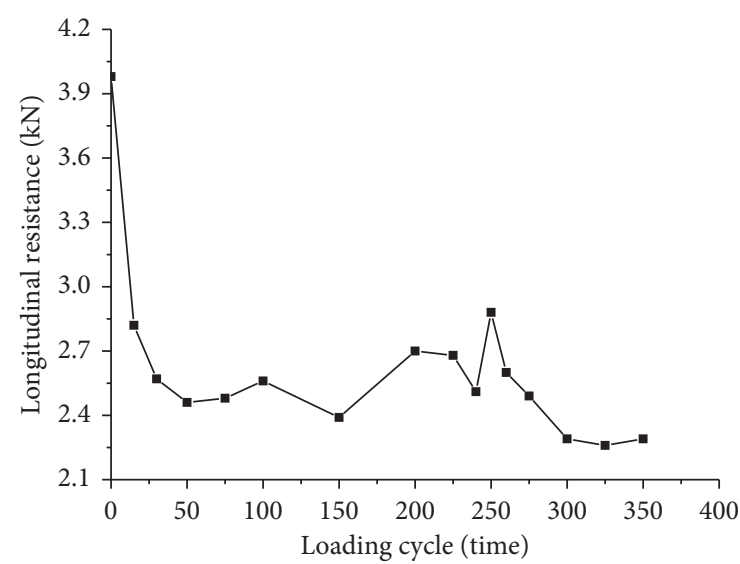

FIGURE 6: Relationship between longitudinal resistance and the loading cycle at $0.5 \mathrm{~mm}$ displacement.

displacement of the composite pad recorded/observed, it is clear that the displacement of the pad is a factor affecting the fluctuations in the longitudinal resistance of the fastener. In summary, it can be deduced that if the reciprocating loading test would be continued, the sliding resistance of the fastener would continue to decrease, and the displacement of the pad would continue to increase; however, the scope of the change would decrease.

It can be seen from Figures 9 and 10 that as the displacement of the pad increases, the longitudinal resistance of the fastener corresponding to $0.5 \mathrm{~mm}$ displacement first decreases quickly and then gradually decreases, while the sliding resistance of the fastener rapidly increases and then slowly decreases. This is a clear indication that the displacement of the pad has a great influence on both the longitudinal resistance of the fastener corresponding to the $0.5 \mathrm{~mm}$ displacement and the sliding resistance of the fastener. In summary, the main reason for the tendency demonstrated above, between the initial loading state and the $225^{\text {th }}$ loading cycle, is the repeated friction between the composite pad, the rail, and the iron pad, which causes the lower surface of the fastener pad to become worn out and rough. Therefore, the friction coefficient is greatly increased. During this process, the displacement of the pad is relatively small, and the longitudinal resistance of the fastener is less

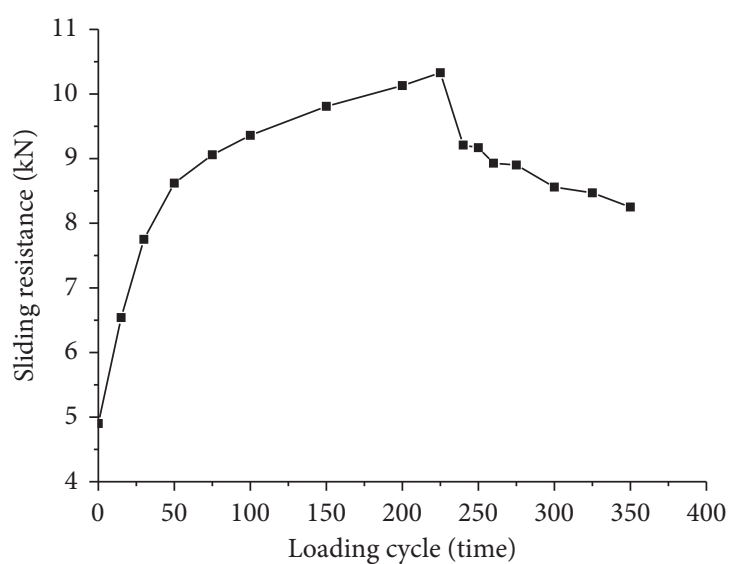

FIGURE 7: Relationship between sliding resistance and the loading cycle.

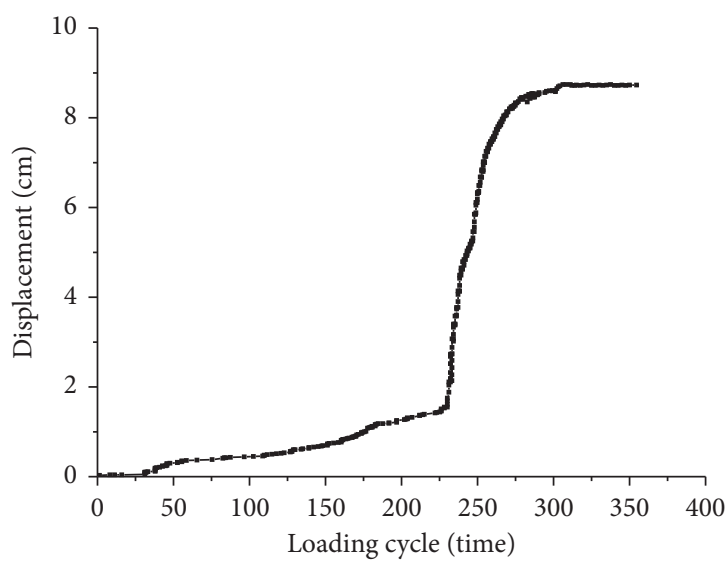

FIGURE 8: Relationship between pad displacement and the loading cycle.

affected. As the number of loadings continues to increase, the surface of the pad wears to some extent and the pad continues to slide. The contact surface area of the pad with the rail and the iron pad is reduced, and thus, the friction is reduced. The influence of the pad displacement is large, so the longitudinal resistance of the fastener is reduced in the post-test phase. 


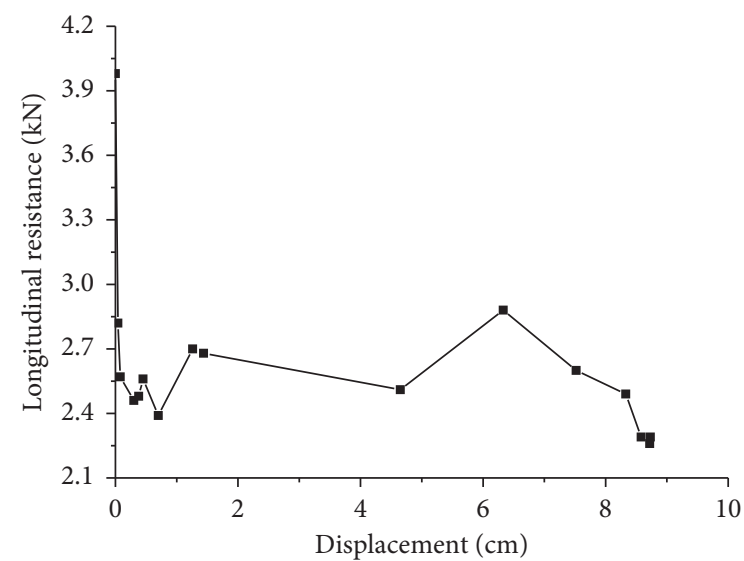

FIGURE 9: Relationship between longitudinal resistance and pad displacement at $0.5 \mathrm{~mm}$ displacement.

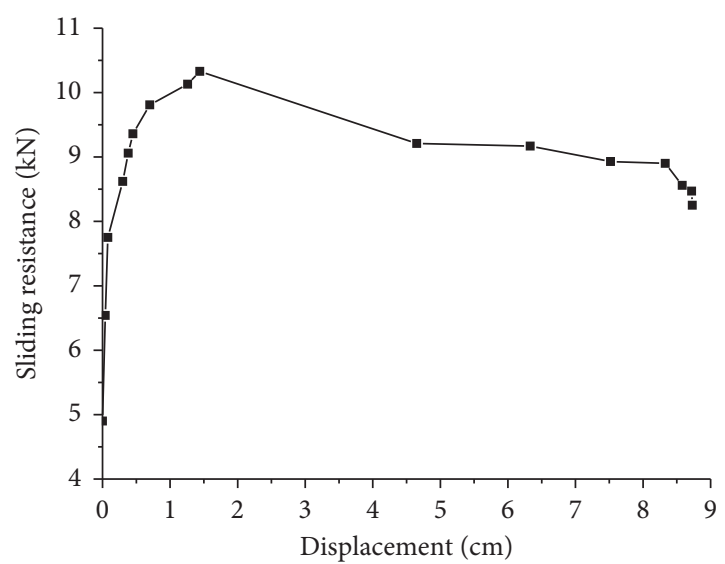

Figure 10: Relationship between fastener sliding resistance and pad displacement.

\section{Conclusions}

Through a reciprocating tensile test of a WJ-8 type resistance fastener, the following research conclusions were obtained:

(1) With the increase in the number of reciprocating loadings, the longitudinal resistance of the small fastener corresponding to the $0.5 \mathrm{~mm}$ displacement gradually reduced, while the sliding resistance of the fastener initially increased and subsequently decreased. Contrastingly, the displacement of the composite pad increased slowly at first until the displacement of the pad reached $1.44 \mathrm{~cm}$ and then more rapidly increased until the displacement of the pad reached approximately $8 \mathrm{~cm}$. Therefore, the critical pad displacement of the fastener in normal operation and failure was about $1.5 \mathrm{~cm}$.

(2) With the increase in the displacement of the pad, the longitudinal resistance of the small resistance fastener corresponding to the $0.5 \mathrm{~mm}$ displacement first experienced first quick decrease, and subsequently, the decrease slowed down, while the sliding resistance of the fastener increased rapidly and then slowly decreased.
(3) During the reciprocating loading process, two factors affect the longitudinal resistance of the fastener: the surface roughness of the composite pad and the displacement of the pad. The surface roughness of the pad is more pronounced in the early stage of reciprocating loading and constitutes the main influencing factor, while the displacement of the pad takes the central role in the later stage.

(4) Replacement of the ageing pad in time is recommended. The pad can be replaced by new materials developed to reduce its longitudinal resistance. This paper can serve as a reference guide for the maintenance of ballastless track fasteners.

\section{Data Availability}

The experimental data used to support the findings of this study are available from the corresponding author upon request.

\section{Conflicts of Interest}

The authors declare that there are no conflicts of interest regarding the publication of this article.

\section{Acknowledgments}

The work described here was supported by the Major Program of the National Natural Science Foundation of China (grant no. 11790283), the High-Speed Railway Joint Fund of the National Natural Science Foundation of China (grant no. U1734208), and the Hunan Provincial Natural Science Foundation of China (grant no. 2019JJ40384).

\section{References}

[1] B. Yan, G.-l. Dai, and H.-p. Zhang, "Beam-track interaction of high-speed railway bridge with ballast track," Journal of Central South University, vol. 19, no. 5, pp. 1447-1453, 2012.

[2] J. Luo and Z. Zeng, "A novel algorithm for longitudinal trackbridge interactions considering loading history and using a verified mechanical model of fasteners," Engineering Structures, vol. 183, pp. 52-68, 2019.

[3] Y. Luo, "A model for predicting the effect of temperature force of continuous welded rail track," Proceedings of the Institution of Mechanical Engineers, Part F: Journal of Rail and Rapid Transit, vol. 213, no. 2, pp. 117-124, 1999.

[4] J. Zhang, D. J. Wu, and Q. Li, "Loading-history-based trackbridge interaction analysis with experimental fastener resistance," Engineering Structures, vol. 83, pp. 62-73, 2015.

[5] D. Gong-Lian, G. E. Hao, L. Wen-Shuo, S. U. Miao, and C. S. University, "Analysis of longitudinally connected ballastless track on the high-speed railway long-span bridge based on the actual measured temperature," Journal of Railway Engineering Society, vol. 34, no. 5, pp. 26-31+93, 2017.

[6] R. Chen, P. Wang, and X. K. Wei, "Track-bridge longitudinal interaction of continuous welded rails on arch bridge," Mathematical Problems in Engineering, vol. 2013, Article ID 494137, 8 pages, 2013.

[7] B. Yan, G.-l. Dai, W.-h. Guo, and Q.-y. Xu, "Longitudinal force in continuously welded rail on long-span tied arch 
continuous bridge carrying multiple tracks," Journal of Central South University, vol. 22, no. 5, pp. 2001-2006, 2015.

[8] P. Ruge and C. Birk, "Longitudinal forces in continuously welded rails on bridgedecks due to nonlinear track-bridge interaction," Computers \& Structures, vol. 85, no. 7-8, pp. $458-475,2007$.

[9] P. Ruge, D. R. Widarda, G. Schmälzlin, and L. Bagayoko, "Longitudinal track-bridge interaction due to sudden change of coupling interface," Computers \& Structures, vol. 87, no. 12, pp. 47-58, 2009.

[10] L.-Y. Shao, M. Zhang, K. Xie, X. Zhang, P. Wang, and L. Yan, "The longitudinal force measurement of CWR tracks with hetero-cladding FBG sensors: a proof of concept," Sensors, vol. 16, no. 12, p. 2184, 2016.

[11] L. Xu, Z. Yu, and C. Shi, "A matrix coupled model for vehicleslab track-subgrade interactions at 3-D space," Soil Dynamics and Earthquake Engineering, vol. 128, p. 105894, 2020.

[12] P. Lou, J. Zhu, G. Dai, and B. Yan, "Experimental study on bridge-track system temperature actions for Chinese highspeed railway," Archives of Civil and Mechanical Engineering, vol. 18, no. 2, pp. 451-464, 2018.

[13] Z. Min, "Mechanics analysis of the rail fastening of bi-block ballastless track on the bridge terminal," Journal of Railway Engineering Society, vol. 26, no. 2, pp. 56-31+63, 2009.

[14] G.-1. Dai and W.-s. Liu, "Applicability of small resistance fastener on long-span continuous bridges of high-speed railway," Journal of Central South University, vol. 20, no. 5, pp. 1426-1433, 2013.

[15] L. Xu, J. Gao, and W. Zhai, "On effects of rail fastener failure on vehicle/track interactions," Structural Engineering and Mechanics, vol. 63, no. 5, pp. 659-667, 2017.

[16] I. A. Carrascal, J. A. Casado, J. A. Polanco, and F. GutiérrezSolana, "Dynamic behaviour of railway fastening setting pads," Engineering Failure Analysis, vol. 14, no. 2, pp. 364373, 2007.

[17] J. A. Casado, I. Carrascal, J. A. Polanco, and F. GutiérrezSolana, "Fatigue failure of short glass fibre reinforced PA 6.6 structural pieces for railway track fasteners," Engineering Failure Analysis, vol. 13, no. 2, pp. 182-197, 2006.

[18] P. Szurgott, P. Gotowicki, and T. Niezgoda, "Numerical analysis of a shaped rail pad under selected static load," Journal of Kones, vol. 19, pp. 407-414, 2012.

[19] H.-U. Bae, S.-J. Park, K.-M. Yun, B.-H. Park, and N.-H. Lim, "Statistical characteristics for longitudinal friction behavior of rail fastening system for concrete track," Journal of the Korea Academia-Industrial Cooperation Society, vol. 16, no. 11, pp. 7870-7877, 2015.

[20] D. J. Thompson and J. W. Verheij, "The dynamic behaviour of rail fasteners at high frequencies," Applied Acoustics, vol. 52, no. 1, pp. 1-17, 1997.

[21] J. Oda, K. Yamazaki, H. Yoshida, and K. Nakada, "An analytical and experimental investigation of rail fastening systems in travelling cranes," International Journal of Mechanical Sciences, vol. 25, no. 12, pp. 935-944, 1983.

[22] J. A. Casado, I. Carrascal, S. Diego, J. A. Polanco, F. GutiérrezSolana, and A. García, "Mechanical behavior of recycled reinforced polyamide railway fasteners," Polymer Composites, vol. 31, no. 7, pp. 1142-1149, 2010.

[23] P. Szurgott and K. Bernyś, "Preliminary numerical analysis of selected phenomena occurring in a rail fastening system," Journal of Kones, vol. 19, pp. 607-614, 2012.

[24] X. Yuan, S. Zhu, L. Xu, W. Zhai, and H. Li, "Investigation of the vibration isolation performance of floating slab track with rubber bearings using a stochastic fractional derivative model," Proceedings of the Institution of Mechanical Engineers, Part F: Journal of Rail and Rapid Transit, vol. 234, no. 9, pp. 992-1004, 2019.

[25] Z. Zeng, C. Tian, Q. Tu, A. A. Shuaibu, and W. Wang, "Experimental study on the longitudinal resistance of WJ-8 fasteners subjected to torque and vertical loading in continuously welded rails," Proceedings of the Institution of Mechanical Engineers, Part F: Journal of Rail and Rapid Transit, Article ID 0954409719880667, 2019.

[26] C. Popov, Principles and Applications of Contact Mechanics and Tribology, Tsinghua University Press, Beijing, China, 2011.

[27] R. B. King and J. K. Lancaster, "Wear of metals by elastomers in an abrasive environment," Wear, vol. 61, no. 2, pp. 341-352, 1980.

[28] K. Ab-Malek and A. Stevenson, "On the lubrication and wear of metal by rubber," Journal of Materials Science, vol. 19, no. 2, pp. 585-594, 1984.

[29] J. M. Charrier, S. G. Maki, and J. P. Chalsfoux, "Penetration of elastomeric block by needles," Journal of Elastomers and Plastics, vol. 18, pp. 200-210, 1986.

[30] L. Gao, Research on Key Technologies of High Speed Railway CWR, China Railway Press, Beijing, China, 2012. 